\title{
ARTIGO
}

DOI: https://doi.org/10.22481/praxis.v15i31.4674

\section{AÇÕES DE FORMAÇÃO CONTINUADA: PERCEPÇÕES DE DOCENTES DOS ANOS INICIAIS DO ENSINO FUNDAMENTAL}

\author{
CONTINUING EDUCATION ACTIONS: TEACHERS PERCEPTIONS OF EARLY \\ YEARS OF ELEMENTARY EDUCATION
}

\section{ACCIONES DE FORMACIÓN CONTINUADA: PERCEPCIONES DE DOCENTES DE LOS AÑOS INICIALES DE LA ENSEÑANZA FUNDAMENTAL}

\author{
Valdicléa Machado da Silva \\ Rede Municipal de Educação de Joinville - Brasil \\ Márcia de Souza Hobold \\ Universidade Federal de Santa Catarina - Brasil
}

\begin{abstract}
Resumo: Este artigo apresenta as percepções de docentes em relação às ações de formação continuada oferecidas por uma Rede Municipal de Ensino. Trata-se de uma pesquisa de cunho qualitativo, em que se lançou mão da entrevista semiestruturada como instrumento para coleta de dados. Os principais aportes que constituem a pesquisa são: Marcelo García (1999), Imbernón (2009, 2010, 2011), Formosinho (2009), Nóvoa (1991a, 1991b, 2002), Romanowski (2007) e Freire (1998). Os resultados deste estudo apontaram que os docentes necessitam que as ações de formação continuada promovam uma aproximação entre teoria e prática e que suas expectativas e necessidades de formação sejam tomadas como ponto de partida ao planejar essas ações. Os dados indicaram que os cursos mais contributivos são aqueles que oferecem uma continuidade do processo formativo, que contemplam as experiências dos professores e que propiciam a socialização dos seus sucessos e suas dificuldades, em um espaço coletivo de aprendizagem.
\end{abstract}

Palavras-chave: Anos Iniciais do Ensino Fundamental. Desenvolvimento profissional docente. Formação continuada de professores.

Abstract: This article presents the perceptions of teachers according to the actions of continuing education offered by a Municipal School. This is a qualitative study, where semi-structured interviews were used as a tool for collecting data. The main theoretic inputs constituting this research are: Marcelo García (1999), Imbernon (2009; 2010; 2011), Formosinho (2009), Nóvoa (1991a; 1991b; 2002), Romanowski (2007) and Freire (1998). Results of this study indicated that teachers need that the actions of continuing education promote a rapprochement between theory and practice, and that their expectations and training needs can be taken as a starting point when planning these actions. The data showed that the courses that contribute the most are those, which offer a continuity of the training 
process, which include teacher's experiences, providing socialization of their successes and difficulties, in a collective learning space.

Keywords: Early years of elementary school. Teachers continuing education. Teachers professional development.

Resumen: Este artículo presenta las percepciones de docentes en relación a las acciones de formación continuada ofrecidas por una Red Municipal de Enseñanza. Se trata de una investigación de cuño cualitativo, en la que se echó mano de la entrevista semiestructurada como instrumento para la recolección de datos. Los principales aportes que constituyen la investigación son: Marcelo García (1999), Imbernón (2009, 2010, 2011), Formosinho (2009), Nóvoa (1991a, 1991b, 2002), Romanowski (2007) y Freire (1998). Los resultados de este estudio apuntaron que los docentes necesitan que las acciones de formación continuada promuevan una aproximación entre teoría y práctica y que sus expectativas y necesidades de formación sean tomadas como punto de partida al planear esas acciones. Los datos indicaron que los cursos más contributivos son aquellos que ofrecen una continuidad del proceso formativo, que contemplan las experiencias de los profesores y que propician la socialización de sus éxitos y sus dificultades, en un espacio colectivo de aprendizaje.

Palabras clave: Años iniciales de la enseñanza fundamental. Desarrollo profesional docente. Formación continuada de profesores.

\section{Introdução}

O desafio de transformar a escola em um espaço mais democrático, onde as práticas educativas sejam ressignificadas e resultem em contribuições para a aprendizagem dos estudantes, em face do processo de democratização do ensino e da complexa tarefa que é 'serprofessor' na atualidade, tem se tornado constante para os profissionais da área educacional, principalmente em relação à formação continuada de professores.

De modo geral, as iniciativas promovidas tanto pela esfera pública quanto pela privada revelam dificuldades em articular pesquisa, formação e inovação pedagógica. Todavia o aspecto que tem sido mais discutido é a dificuldade dos formadores de se aproximarem dos reais contextos escolares brasileiros, haja vista que, por falta de políticas públicas direcionadas para a formação continuada, na maioria das vezes, os cursos mais oferecidos são os de curta duração, apresentados aos docentes de forma pontual e assistemática, para sanar desafios momentâneos.

De acordo com Gatti (2008), o surgimento de tantos tipos de formação no Brasil tem bases históricas nas condições emergentes da sociedade contemporânea, quando foram criados os discursos para a atualização. Esses discursos estão presentes: 
[...] nos desafios colocados aos currículos e ao ensino, nos desafios postos aos sistemas pelo acolhimento cada vez maior de crianças e jovens, nas dificuldades do dia-a-dia nos sistemas de ensino, anunciadas e enfrentadas por gestores e professores e constatadas e analisadas por pesquisas. (GATTI, 2008, p. 58).

Diante desses desafios enfrentados no atual cenário educacional brasileiro, é preciso considerar que ser professor é estar em permanente constituição/formação, é criar espaços para refletir individual e coletivamente sobre as dificuldades enfrentadas no cotidiano da sala de aula. Em vista disso, no intuito de melhor compreender esse cenário, a presente investigação tem como objetivo central conhecer as percepções dos professores dos anos iniciais do Ensino Fundamental acerca das ações de formação continuada oferecidas pela Rede Municipal de Ensino.

Entende-se que é preciso estar atento às percepções dos professores. Libâneo (2004, p. 227) realça o papel importante acerca da reflexão coletiva, quando afirma que "[...] a formação continuada pode possibilitar a reflexividade e a mudança nas práticas docentes, ajudando os professores a tomarem consciência das suas dificuldades, compreendendo-as e elaborando formas de enfrentá-las". O autor ainda adverte que "não basta saber sobre as dificuldades da profissão, é preciso refletir sobre elas e buscar soluções, de preferência, mediante ações coletivas".

Sobre esse viés, compreende-se que, por melhor que tenha sido a formação inicial do professor, esta se constitui apenas na primeira parte do processo de formação docente, que precisa ser sólida, haja vista que, segundo Tardif (2012), os saberes iniciais, confrontados com as experiências vividas no exercício da profissão docente, deverão ser reelaborados continuamente e ressignificados ao longo de seu desenvolvimento profissional.

Desse modo, pode-se inferir que a formação continuada deve ser algo dinâmico, considerando-se que o processo de aquisição do conhecimento é contínuo, pois se entende que ser professor é estar em permanente constituição, é criar espaços para refletir individual e coletivamente sobre as dificuldades enfrentadas no cotidiano de sala de aula, não bastando apenas acumular teorias; cumpre, sobretudo, saber organizá-las e interpretá-las, de modo a transformar e ressignificar suas práticas.

Sobre os conceitos de formação continuada e desenvolvimento profissional, buscou-se o apoio teórico de autores como: Marcelo García (1999), Formosinho (2009), Nóvoa (1991a), Imbernón (2009) e Vaillant \& Marcelo García (2012), os quais vêm centrando suas discussões no conceito de desenvolvimento profissional docente (em substituição à formação continuada), dessa forma, há uma conotação de evolução e continuidade, que, segundo 
Vaillant e Marcelo García (2012), supera a justaposição entre a formação inicial e o aperfeiçoamento de docentes.

\section{As implicações da formação continuada no desenvolvimento profissional dos professores: alguns conceitos}

Marcelo García (1999) sintetiza a formação continuada como uma área do conhecimento, da investigação e de propostas teóricas centrada no estudo dos processos. No âmbito da didática e da organização escolar, esta área:

[...] estuda os processos através dos quais os professores - em formação ou em exercício - se implicam individualmente ou em equipe, em experiências de aprendizagem através das quais adquirem ou melhoram os seus conhecimentos, competências e disposições, e que lhes permite intervir profissionalmente no desenvolvimento do seu ensino, do currículo e da escola, com o objetivo de melhorar a qualidade da educação que os alunos recebem. (MARCELO GARCÍA, 1999, p. 26).

Para o autor, aprender a ensinar não é um processo homogêneo, ou seja, não acontece da mesma forma para todos, porém se faz necessário conhecer as características pessoais, cognitivas, contextuais e relacionais de cada professor de modo a desenvolver suas próprias capacidades e potencialidades.

Já para Formosinho (2009) e Nóvoa (2002), a formação continuada pode ser compreendida como a promoção da aprendizagem dos saberes profissionais inerentes ao desempenho docente. Segundo os autores, estes saberes profissionais configuram competências profissionais, pois consubstanciam teorias, práxis, relações e afetos, valores e normas mobilizáveis para a ação do professor, realizáveis não apenas em situações formais mas também por meio de socializações.

Ainda que reconheça a importância do papel dos formadores das instituições de ensino superiores na formação docente, desde que haja o confronto entre a prática e as propostas pedagógicas, para Formosinho (2009), a formação mais significativa é aquela que ocorre nos contextos de trabalho, na escola, na/pela aprendizagem com os outros docentes. Este mesmo autor ainda adverte: "[...] espera-se que a gestão e a formação centrada na escola maximizem a sabedoria e as competências acumuladas dos professores, sobretudo da equipe dirigente" (FORMOSINHO, 2009, p. 268).

Nessa perspectiva, compreende-se que é na escola que as práticas formativas se articulam com os contextos sociais dos professores e da comunidade escolar. Os professores 
passam a ter um papel ativo na construção do saber, sendo considerados 'sujeitos', e não apenas 'objetos' ou 'destinatários', deixando de ser meros consumidores passivos de programas de formação.

Dessa forma, vê-se corroborada a compreensão de Formosinho (2009) nas afirmações de Romanowski (2007) e Imbernón (2009), que também consideram de fundamental importância que os professores participem do processo de planejamento, execução e avaliação dos resultados da formação, bem como que as opiniões dos docentes sejam consideradas para o planejamento dos processos formativos.

Sobre o conceito de desenvolvimento profissional, Marcelo García (1999) afirma que este sofreu modificações na última década, em decorrência do entendimento de como ocorrem os processos de aprender a ensinar. Segundo o autor, o desenvolvimento profissional passa a ser considerado “[...] um processo em longo prazo, no qual se integram diferentes tipos de oportunidades e experiências planificadas sistematicamente para promover o crescimento e o desenvolvimento profissional” (MARCELO GARCÍA, 1999, p. 7).

Formosinho (2009) contribui com esta questão, afirmando que a formação contínua e o desenvolvimento profissional "[...] são perspectivas diferentes sobre a mesma realidade, que é a educação permanente dos professores num processo de ciclo de vida" (FORMOSINHO, 2009, p. 225).

Entende-se, portanto, que a formação continuada se encontra inserida no processo de constituição da ação docente e é parte significativa e permanente do desenvolvimento profissional dos professores.

Assim sendo, é necessário também analisar outros aspectos relevantes, que contribuirão ou não para o desenvolvimento profissional dos professores. Aspectos esses referenciados por Marcelo García (1999) e Imbernón (2011), os quais consideram que eles podem possibilitar ou impedir a progressão do professor, pois estão “[...] intrinsecamente relacionados com a melhoria das suas condições de trabalho e com a possibilidade institucional de melhores índices de autonomia e capacidade de acção dos professores e colectivamente" (MARCELO GARCÍA, 1999, p. 144).

Sobre esse viés, considerando o contexto atual, Imbernón (2011, p. 45) corrobora a afirmação acima, ponderando que:

[...] a melhoria da formação ajudará esse desenvolvimento, mas a melhoria de outros fatores (salários, estruturas, níveis de decisão, níveis de participação, carreira, clima de trabalho, legislação trabalhista etc.) tem papel decisivo nesse desenvolvimento. 
Outro fator importante sobre o desenvolvimento profissional dos professores é que ele não pode ser analisado somente do ponto de vista dos conhecimentos individuais, haja vista, conforme Nóvoa (1991a), que superar essa concepção significa reconhecer que o espaço da formação contínua é, portanto, o do professor, em suas dimensões coletiva, profissional e organizacional, contribuindo para a emancipação profissional e para a autonomia na produção dos saberes e valores.

Nesse sentido, referindo-se aos programas/ações de formação continuada, Imbernón (2011) reconhece que a opinião do professorado deve ser considerada no momento do planejamento, da execução e da avaliação dos resultados da formação. O autor sugere a promoção de uma formação que facilite a reflexão, para que seja possível auxiliar os professores a se tornarem "[...] melhores planejadores e gestores do ensino-aprendizagem e, por que não, agentes sociais capazes de intervir também nos complexos sistemas éticos e políticos que compõem a estrutura social e de trabalho" (IMBERNÓN, 2011, p. 27).

E ainda explicita que os professores só veem a formação como um benefício quando percebem que o novo programa formativo teve repercussão na aprendizagem de seus estudantes, supondo um benefício para o alunato e, consequentemente, na forma de exercer a docência, então “[...] abre-se a forma de ver a formação não tanto como uma 'agressão' externa, mas como um benefício individual e coletivo" (IMBERNÓN, 2011, p. 27).

Contudo, considerando-se estes aportes teóricos, compreende-se que é preciso ouvir os professores, para que seja possível planejar os momentos de formação continuada, a fim de que busquem novas estratégias que fundamentem e auxiliem o desenvolvimento profissional e a valorização da profissão docente.

Os formadores de professores precisam oportunizar o desenvolvimento de novos conhecimentos que contribuam com a formação de professores críticos e reflexivos sobre suas ações e responsabilidades perante os desafios de ensinar os estudantes para a criticidade e para a conscientização da cidadania.

\section{O caminho metodológico da pesquisa}

A presente pesquisa constitui-se pelos indicadores da abordagem qualitativa. Optou-se por coletar dados recorrendo-se a entrevistas semiestruturadas, por se acreditar que, lançando mão desse instrumento, seria possível obter uma maior aproximação com os dados que se pretendia analisar, propiciada pela interação entre professores participantes e pesquisadora. 
Os participantes desta investigação foram dezoito professoras e dois professores dos anos iniciais do Ensino Fundamental de escolas urbanas da Rede Municipal de uma cidade localizada no sul do país, contatados por meio de uma carta, que os convidava a participar da entrevista como voluntários anônimos.

Os critérios para a participação nas entrevistas foram os seguintes: que fossem professores dos anos iniciais do Ensino Fundamental, com formação inicial em Pedagogia e vinculação efetiva, ou seja, que tivessem ingressado na Rede Municipal de Ensino por meio de concurso público e firmado contrato com carga horária de 40 horas/aulas semanais, que tivessem finalizado o período probatório (há mais de três anos na Rede) e estivessem atuando em sala de aula, independentemente de idade ou sexo.

Diante da existência de cinquenta escolas urbanas na Rede Municipal de Ensino que atendem crianças do $1^{\circ}$ ao $9^{\circ}$ ano do Ensino Fundamental e para que se obtivesse uma amostra representativa de professores que lecionassem em regiões diversificadas do município, optouse por sortear vinte escolas com auxílio do programa Statistical Package for the Social Sciences (SPSS), o qual selecionou cinco unidades escolares por região da cidade (Norte, Sul, Leste e Oeste).

Após o sorteio das vinte escolas, de posse do número de professores que se encaixavam nos critérios estabelecidos para a participação na pesquisa, as referidas cartas foram entregues aos supervisores escolares durante duas reuniões, propiciadas à pesquisadora por parte da Secretaria da Educação, para que se mencionassem os objetivos da pesquisa. Durante a apresentação do projeto, foi solicitado o auxílio das supervisoras, para que explicassem aos professores a intenção da pesquisa e entregassem as cartas diretamente aos docentes, em cada unidade de ensino.

No total, foram entregues 132 cartas, número correspondente à quantidade de professores que atendiam aos critérios de inclusão desta investigação, de acordo com levantamento prévio realizado com a secretaria das próprias escolas que foram sorteadas para participar da pesquisa.

Das 132 cartas-convite entregues, 40 retornaram preenchidas com os dados dos professores que tinham interesse em conceder a entrevista, o que corresponde a quase $30 \%$ de retorno. No entanto, destas últimas, dez cartas foram respondidas por professores que não trabalhavam 40 horas em salas de aula regular $\left(1^{\circ}\right.$ ao $5^{\circ}$ ano), pois se tratava de professores que não se incluíam em um dos critérios para a participação, tendo em vista que trabalhavam 
apenas por 20 horas em sala regular e, no período oposto, atuavam como professores de música, em salas de Apoio Pedagógico ou, ainda, coordenavam o Laboratório de Informática.

Restaram 30 aceites, 10 a mais do que o estabelecido para as entrevistas. Por essa razão, foi feita uma lista dos professores interessados, a fim de identificar as turmas/anos em que lecionavam, procedendo-se, em seguida, a uma nova seleção, com ênfase na representatividade, ao fim da qual seriam escolhidos 20 professores que atuassem em anos diversificados, possibilitando assim que fossem ouvidas diferentes experiências de formação, do $1^{\circ}$ ao $5^{\circ}$ ano.

Após definição dos participantes da pesquisa, foi realizado o contato, via telefone e email, para agendamento das entrevistas em locais e horários estabelecidos pelos professores. Foram realizadas no total vinte (20) entrevistas com os professores dos anos iniciais do Ensino Fundamental, contemplando-se as vozes de docentes de diferentes contextos socioeconômico da cidade. Também se estabeleceu contato com os professores interessados em colaborar com a pesquisa, mas que não atendiam aos critérios estabelecidos para a investigação, a fim de agradecer-lhes e explicar os motivos da não realização da entrevista.

As transcrições das falas dos docentes foram organizadas em uma planilha do Excel, seguindo as perguntas do roteiro da entrevista, as quais foram agrupadas, após muitas leituras, por questão de pesquisa, para posterior análise. Para proceder à análise das percepções dos professores sobre as ações de formação continuada oferecidas pela Rede, foram consideradas as respostas das seguintes perguntas: "Como você avalia as ações de formação continuada promovidas pela Rede Municipal de Ensino?", "Você poderia destacar quais ações tiveram maior influência na sua prática docente?" e "Você considera que as ações de formação continuada contribuem para o seu desenvolvimento profissional? De que forma?”.

No intuito de garantir confiabilidade e validade à pesquisa, interpretações foram sendo construídas, baseadas nos dados obtidos por meio das vozes dos professores. Esses dados, confrontados com os documentos nacionais, estaduais e municipais, foram estudados utilizando-se a análise de conteúdo, que, segundo Franco (2012), configura-se em uma abordagem metodológica crítica e dinâmica da linguagem, pois reconhece o papel ativo do sujeito na produção do conhecimento. O projeto de pesquisa já havia sido aprovado antes do contato com os professores pelo Comitê de Ética de Pesquisa com seres humanos, e todos os participantes assinaram o Termo de Consentimento Livre e Esclarecido (TCLE). 


\section{As percepções dos professores sobre as ações de formação continuada promovidas pela Rede Municipal de Ensino}

Um dado inicial sobre a avaliação da formação oferecida aos professores dos anos iniciais do Ensino Fundamental, relativo à quantidade e à frequência com que os cursos são oferecidos pela Rede, indica que dos 20 entrevistados, 13 professores consideram que esses cursos são em número reduzido, insuficientes para a sua prática profissional e que deveriam ser oferecidos em maior quantidade. Destacam-se aqui algumas falas:

Eu acredito que são em número reduzido. [...] É difícil ter essa disponibilidade de horário, mas eu penso que deveriam ser oferecidos mais cursos (P1).

Há quatro anos eu acho que foi feito esse curso e de lá para cá não foi mais oferecido (P6).

Insuficiente, passaram-se longos períodos sem formação, [...] sem sequência, ou seja, muitas vezes começam um projeto e o interrompem. Outras vezes eles ficam muito distanciados uns dos outros (P14).

Apesar de terem relatado que a oferta de cursos é insuficiente, uma leitura mais aprofundada das respostas destacou que esses professores demonstram considerar a formação continuada como fator essencial para o seu desenvolvimento profissional: "Se bem organizados, os cursos podem ser enriquecedores para o nosso desenvolvimento" (P1).

Os professores, em geral, referem-se à falta de cursos ou aos poucos cursos, principalmente nos últimos cinco anos (período de 2008 a 2013). Destaca-se uma das falas em que a participante relata a importância dos cursos que fez no início dos anos 2000:

Eu já estou há 18 anos na Rede e já fiz a formação do PROFA ${ }^{l}$, do Mathema, da Escola da Vila [...] foram bastante significativos para a minha prática pedagógica, [...] Deslanchou o nosso trabalho, pois estávamos perdidos em meio às muitas concepções de ensino (P9).

A maioria dos entrevistados (treze) relatou satisfação em ter participado desses cursos e destacou que os novos professores não tiveram este preparo. Formosinho (2009, p. 28) indica que é essencial propiciar aos professores "[...] conhecimentos e competências que farão crescer a sua capacidade de providenciar melhores oportunidades de aprendizagem a todos os

\footnotetext{
${ }^{1}$ PROFA - Programa de Formação de Alfabetizadores - oferecido pelo MEC. As formações do Mathema e da Escola da Vila foram oferecidas pela Rede Municipal, que contratou os serviços de formadores de agências de São Paulo. De acordo com uma das professoras entrevistadas, esses cursos ocorreram nos seguintes períodos: Escola da Vila e estudos dos PCNs (2001); PROFA para alfabetizadores e professores de $2^{\circ}$ ao $4^{\circ}$ ano (agosto de 2002 a julho de 2003), Mathema - 160 horas, $1^{\circ}$ e $2^{\circ}$ ano (de setembro a novembro de 2004) e Mathema de geometria (de abril a julho de 2007). Para participar dessa formação, foram sorteados dois professores e uma supervisora por escola.
} 
seus alunos". São nesses momentos de aprendizagem que o professor percebe que, ao transmitir à profissão maior "[...] competência técnica e flexibilidade nas variadas estratégias de ensino, bem como mais conhecimento sobre os conteúdos a ensinar", ele estará contribuindo também para o seu próprio desenvolvimento profissional (FORMOSINHO, 2009, p. 229).

Ainda que tenham afirmado não ter recebido formações durante um determinado período pela Rede, alguns professores revelaram-se bastante autônomos na busca por formação profissional, como se pode perceber nas falas a seguir:

Se ficar muito tempo sem a gente fazer, a gente tem que buscar [...] não é porque a prefeitura não disponibilizou que a gente não corre atrás (P6).

Porque a formação também não é só no local, a formação às vezes é uma dica, é um mural em que está escrito alguma coisa, isso faz parte da nossa formação, chegar essa informação até nós, algumas coisas são da pessoa, a pessoa tem que buscar (P10).

Fui buscar por conta própria, porque achava insuficientes as oferecidas pela Rede pública (P14).

Tenho me qualificado por conta, por sentir necessidade e prazer em conhecer novas ideias, pois pela Rede tive apenas dois ou três encontros de formação (P20).

Compreender esse processo de autonomia, que passa pela profissionalização dos professores, é um desafio cada vez mais presente, pois os docentes sentem necessidade de serem autores da sua própria busca pelo conhecimento, visando à melhoria dos processos educacionais. De acordo com Nóvoa (1991b, p. 16), “[...] importa valorizar paradigmas de formação que promovam a preparação de professores reflexivos, que assumam a responsabilidade do seu próprio desenvolvimento profissional e que participem como protagonistas na implementação das políticas educativas".

Outro dado importante nas falas dos participantes revela que no ano de 2013 estavam sendo promovidas algumas ações de formação que teriam continuidade em 2014. Entretanto, de acordo com os professores, estas privilegiavam apenas professores do $1^{\circ}$ ao $3^{\circ}$ ano e do $5^{\circ}$ ano, sem que houvesse, na ocasião, um planejamento específico para os professores do $4^{\circ}$ ano.

Ao analisar a planilha de caracterização dos participantes, foi possível perceber que a maioria dos professores que revelaram a falta de formação nos últimos cinco ou oito anos era composta por profissionais que lecionavam há algum tempo para as turmas do $4^{\circ}$ ano, o que sugere uma preocupação maior, por parte dos governos federal, estadual e municipal, com ações de formação continuada que atendam às necessidades dos docentes alfabetizadores, que 
lecionam para turmas do $1^{\circ}$ ao $3^{\circ}$ ano. No Gráfico 1 , demonstram-se os cursos que os professores estavam realizando na época das entrevistas:

Gráfico 1 - Levantamento da participação dos professores em cursos de formação continuada em 2013

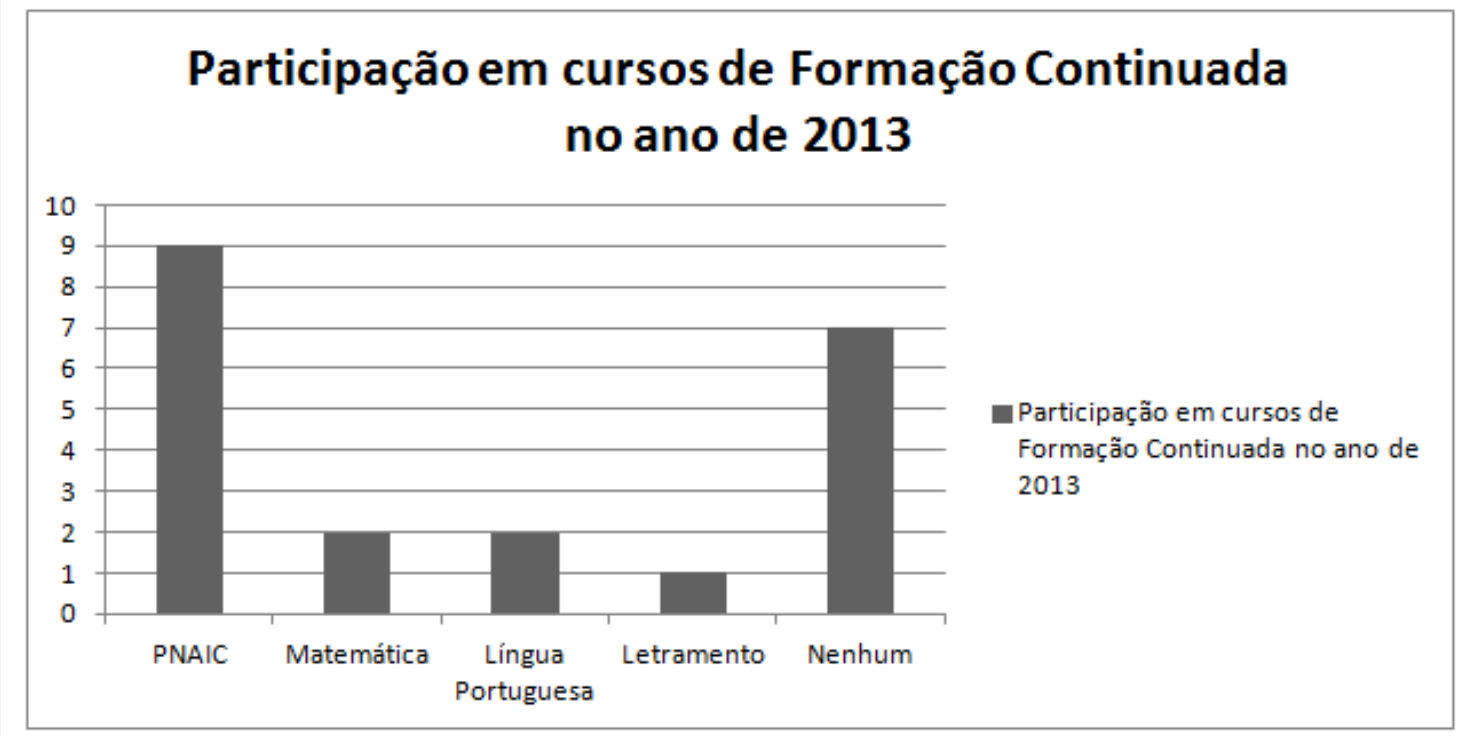

Fonte: Instrumento de pesquisa (2014).

Importante observar que dos nove professores participantes da formação do PNAIC ${ }^{2}$ (Pacto Nacional de Alfabetização na Idade Certa), oferecida aos professores do $1^{\circ}$ ao $3^{\circ}$ ano, a qual, segundo uma das entrevistadas "não é uma ação da Rede, é uma parceria da esfera Federal com a Municipal" [sic] (P1), três professoras participavam paralelamente de outros dois cursos promovidos pela Rede Municipal, direcionados aos docentes que também atuavam em salas do $5^{\circ}$ ano: um de Matemática, e outro sobre Sequências Didáticas em Língua Portuguesa.

Ressalta-se que o número representativo de participações na formação do PNAIC, segundo Frade (ISABEL..., 2012), que é professora da Faculdade de Educação da Universidade Federal de Minas Gerais (UFMG), em entrevista à revista virtual Plataforma do Letramento, é devido à Política Educacional implantada em 2012, que tem como principal objetivo garantir que todas as crianças brasileiras de até oito anos sejam alfabetizadas plenamente. A professora enfatiza a importância de articular as três vertentes do Pacto (avaliação, formação dos professores e material didático), mas atenta para a importância de

\footnotetext{
${ }^{2}$ Lei n. 12.801, de 24 de abril de 2013 - Conversão da Medida Provisória n. 586, de 2012. Dispõe sobre o apoio técnico e financeiro da União aos entes federados no âmbito do Pacto Nacional pela Alfabetização na Idade Certa e altera as Leis n. 5.537, de 21 de novembro de 1968, n. 8.405, de 9 de janeiro de 1992, e n. 10.260, de 12 de julho de 2001.
} 
“[...] haver um processo contínuo de formação e avaliação, e não um abandono após esse processo".

Dessa maneira, a professora da UFMG aponta o diferencial do PNAIC em relação a outras políticas de formação de alfabetizadores: o PNAIC é uma política de continuidade do governo brasileiro voltada à formação dos docentes, que começou com o Programa de Formação de Professores Alfabetizadores (PROFA), criado pelo MEC em 2001, com a proposta de orientar as ações educativas de alfabetização na Educação Infantil, no Ensino Fundamental e na Educação de Jovens e Adultos (EJA). Depois, veio o Pró-Letramento Mobilização pela Qualidade da Educação -, iniciado em 2005. Agora, temos o fortalecimento dessas políticas com o PNAIC, ou seja, a continuidade e a evolução desse processo, e não uma ruptura.

Com relação às ações de formação continuada desenvolvidas pela Rede que foram contributivas para a prática docente e o desenvolvimento profissional, as mais citadas pelos entrevistados, além dos cursos de que estavam participando na ocasião, foram: o PROFA, a Escola da Vila, o Mathema, uma formação de geometria (formadora - professora de matemática da Rede), Letramento e Práticas Infantis (realizado em parceria da Rede com uma universidade do município), um curso na área de Ciências (palestrante - enfermeira de uma Maternidade da região) e uma formação sobre Inclusão Social (professores de uma universidade de um município vizinho). Importante salientar que as referências sobre os três primeiros cursos acima foram dadas por professores que estão na Rede há mais de doze anos. Por outro lado, os oito professores com menor tempo de serviço relataram que não ficavam sabendo das ofertas de cursos importantes, pois não havia divulgação suficiente em suas escolas.

Do questionamento sobre as características dos cursos que trouxeram maior contribuição para o desenvolvimento profissional, foram destacadas as seguintes falas:

Quando o curso é prático e propõe que nós tenhamos também as tarefas, que apliquemos e levemos os resultados para socialização, torna a formação continuada mais rica. Porque a socialização vai nos dar ideias, nos fazer perceber onde estamos errando e como podemos melhorar as nossas práticas $(\mathrm{P} 1)$.

A universidade fez um projeto com as professoras de Letras e tinha sobre a linguística [...] Eles nos possibilitaram aprender novas técnicas por meio da teoria. [...] Era uma vez na semana, depois a cada 15 dias, então observamos a necessidade de entender a língua para poder alfabetizar (P5).

As formadoras desse curso tinham bastante experiência porque eram professoras da Rede. [...] Quando você ministra um curso e pratica aquilo, é 
mais fácil se fazer entender do que uma pessoa que só estuda. Eu comecei a trabalhar com as minhas crianças com mais frequência a geometria (P6).

E ali a gente analisava as possibilidades, e os insucessos. [...] a gente ia aprendendo com aquilo ali e ia desenvolvendo, não ficava só na teoria esquecida (P9).

Durante o curso íamos discutindo, uma ajudava a outra, era uma troca de experiências (P10).

As questões mais importantes para mim eram as técnicas de abordagem, ou seja, como trabalhar com o conteúdo para despertar interesse e atenção do aluno (P14).

Com relação às características dos cursos comentadas pelos respondentes, é possível inferir que a formação mais representativa é aquela em que o professor percebe o seu desenvolvimento profissional, em que lhe é possibilitada a troca de ideias, a que o desafia a criar e mostrar a sua experiência, pois esses aspectos irão refletir em sua prática pedagógica na sala de aula.

Observam-se, na fala dos professores, os aspectos que eles mais apreciam nos cursos de formação continuada: trocas, sugestões, relatos de experiência e reflexão sobre os resultados do processo em que obtiveram resultados positivos na aprendizagem do aluno. Por outro lado, percebe-se que professores com maior experiência precisam de uma motivação maior para participarem nos cursos, pois relatam que neles não se apresentam novidades, como é possível observar na fala da $\mathrm{P} 4:$ " [...] sinceramente, teria que ter muita novidade $e$ coisa muito nova mesmo para poder me chamar atenção um curso. Porque a gente [...] para mudar os teus hábitos, hoje, isso não é fácil".

Marcelo García (1999) apresenta um modelo de mudança do professor baseado em Guskey (1986), partindo do princípio de que as crenças e atitudes dos professores só se modificam se eles observarem resultados positivos na aprendizagem dos alunos. Quando se fala em melhoria, não se está fazendo referência apenas à aprendizagem ou ao desempenho mas também à motivação, à participação e à atitude em face da escola. Ao enfrentar desafios, os professores sofrem pressão para mudar e atender às necessidades dos alunos e da sociedade, entretanto, segundo Duffy e Roehler, citados por Marcelo García, (1999), eles recusam mudanças que sejam complexas, conceituais e longitudinais.

As falas em relação à desmotivação dos professores para participarem das formações continuadas também são destacadas de maneira similar a este estudo na dissertação de Aguiar (2013), intitulada Desenvolvimento Profissional dos Professores dos Anos Iniciais: Contribuições da Formação Continuada, na qual a pesquisadora também buscou 
compreender as ações de formação continuada oferecidas pela Rede Municipal aos professores dos Anos Iniciais, por meio de questionários, contando com 140 professores respondentes.

No que se refere às desmotivações dos professores, a pesquisadora destaca duas falas importantes, que indicam o despreparo dos formadores: "Normalmente os palestrantes $e$ formadores sabem menos que os professores e parecem que estão alheios aos problemas enfrentados pelos professores nas escolas (P76)". E acrescenta: “A Secretaria procura dar formação, mas pecam nos profissionais que administram a formação. Pois muitas vezes não estão na atuação em sala de aula e acabam falando 'utopias' aos quais não vivenciam diariamente (P102)" (AGUIAR, 2013, p. 72).

Esta mesma pesquisa também relata a existência de uma prática comum em cursos de formação continuada, a de trazer especialistas em autoajuda para falar aos professores, o que vai de encontro às necessidades destes profissionais.

Dessa maneira, é possível perceber, por meio das 'vozes' dos docentes, a relevância da participação dos professores na hora de pensar a formação continuada. Imbernón (2010, p. 32) afirma que é de fundamental importância que:

[...] no momento de planejar a formação, executá-la e avaliar seus resultados, os professores participem de todo o processo e que suas opiniões sejam consideradas. Somente quando os professores constatam que o novo programa formativo ou as possíveis mudanças que a prática oferece repercutirão na aprendizagem de seus alunos, mudarão suas crenças e atitudes de maneira significativa, supondo um benefício para os estudantes e para a atividade docente. É quando a formação será vista como um benefício individual e coletivo, e não como uma 'agressão' externa ou uma atividade supérflua.

$\mathrm{Na}$ perspectiva de tentar conhecer as percepções dos professores dos Anos Finais $\left(6^{\circ}\right.$ ao $9^{\circ}$ ) da mesma Rede de Ensino em que fora realizada esta pesquisa, Menslin (2012) indica nos resultados de seu estudo que os conteúdos trabalhados nos cursos são repetitivos e pouco contributivos para a melhoria do repertório da prática docente. Essa constatação vem de encontro ao que pensam os professores dos Anos Iniciais ouvidos na presente pesquisa, principalmente os do $1^{\circ}$ ao $3^{\circ}$ ano, quando relatam que, embora às vezes sejam em número reduzido, principalmente nos últimos cinco anos, os cursos ofertados foram a base de sustentação para sua prática profissional, base esta que lhes faltou na formação inicial.

Ao se fazer uma leitura das falas dos docentes de ambas as pesquisas (MENSLIN, 2012; AGUIAR, 2013), as afirmações parecem indicar que as ações de formação continuada 
destinadas aos profissionais dos Anos Iniciais participantes da presente pesquisa foram mais significativas.

Desse modo, entende-se que, muito além das ações pontuais de formação continuada, que às vezes são oferecidas aos professores, geralmente organizadas de modo a sanar alguma dificuldade, como a aplicação de inovações tecnológicas, os 'modismos' no processo de ensino-aprendizagem e as orientações pedagógicas para a implantação de novas leis, entre outras, os professores sinalizam que precisam de uma formação que realmente seja mais efetiva, para que eles possam vislumbrar resultados contínuos no seu espaço de experiência e de construção de conhecimento, que é a sala de aula.

\section{Algumas considerações}

A pesquisa desvelou alguns aspectos que precisam ser pensados durante o planejamento de ações de formação continuada para os professores dos Anos Iniciais do Ensino Fundamental. É possível verificar, por meio da análise de dados, evidências de que os professores desejavam que lhes fossem oferecidos mais cursos e que estes tivessem características sistemáticas, planejadas de forma contínua, a fim de atender às necessidades de atualização do conhecimento com que precisam lidar ao desenvolverem sua prática profissional.

Freire (1998, p. 105) contribuiu com esta questão quando mencionou que “[...] é refletindo sobre a prática que aprendemos a pensar e a praticar melhor", contudo atribuiu valor à prática na mesma proporção que à teoria ao afirmar a dialeticidade existente entre ambas. Ainda segundo o autor, "[...] é desvelando o que fazemos desta ou daquela forma, à luz do conhecimento que a ciência e a filosofia oferecem hoje que nos corrigimos e nos aperfeiçoamos" (FREIRE, 1998, p. 105).

A fala dos participantes confirma a perspectiva dos teóricos que embasam esta investigação: é preciso que as instituições formativas levem em conta as expectativas e necessidades dos professores, que contemplem as experiências do próprio professor e que possibilitem reflexão sobre a prática profissional. Entende-se que, conhecendo-se os diferentes interesses e expectativas dos professores em formação ou para a sua formação, aumenta-se a possibilidade de êxito nessas ações. 
Importante salientar que, como seres reflexivos, os professores precisam ser considerados como intelectuais capazes de produzir conhecimentos e participar das decisões da instituição de ensino e da comunidade, contribuindo para uma escola mais democrática.

Nesse sentido, o que mais chama a atenção é a autonomia revelada por alguns professores na busca pela sua profissionalização, haja vista que, conforme Nóvoa (1991b.), o espaço da formação contínua é, portanto, o do professor, em suas dimensões coletiva, profissional e organizacional, contribuindo para a sua emancipação profissional e para a autonomia na produção dos seus saberes e valores.

Por outro lado, Merriam e Caffarella (1991 apud MARCELO GARCÍA, 1999, p. 53) conceituam a aprendizagem autônoma como "[...] aquela que inclui todas as atividades de formação na qual a pessoa toma a iniciativa, com ou sem a ajuda de outros, de planificar, desenvolver e avaliar as suas próprias atividades de aprendizagem”. Nesse sentido, entendem que os professores são capazes de tomar decisões e articular normas e limites de aprendizagem, bem como têm a capacidade de autogestão e de aprender com a própria experiência.

Um último fator importante revelado nesta pesquisa foi a importância dada aos cursos de alfabetização oferecidos pelo governo federal, na qual se percebe uma maior preocupação com os aspectos da leitura e da escrita nos três primeiros anos do Ensino Fundamental, fortalecendo as disciplinas de Língua Portuguesa e também de Matemática. Contudo, vale considerar que os professores também mencionaram dificuldades no ensino das áreas de estudo, principalmente nas disciplinas de História, Geografia e Ciências.

As considerações aqui destacadas buscam contribuir para estudos sobre as percepções dos professores dos Anos Iniciais do Ensino Fundamental e permitem refletir sobre como são pensadas/planejadas as ações de formação continuada oferecidas a esses professores.

Entende-se que conhecer o que dizem os professores sobre as suas expectativas e necessidades formativas, abrindo espaço para que suas vozes sejam ouvidas, analisando os contextos socioeconômicos e culturais em que estão inseridos, contribuirá para que os programas de formação continuada possam ser aprimorados e melhor planejados, a fim de que, efetivamente, os professores participem e se tornem mais ativos no seu desenvolvimento profissional. 


\section{REFERÊNCIAS}

AGUIAR, Carina Rafaela. Desenvolvimento profissional dos professores dos anos iniciais do ensino fundamental: contribuições da formação continuada. 2013. 151 f. Dissertação (Mestrado em Educação) - Universidade da Região de Joinville, Joinville, 2013.

ANDRÉ, Marli E. D. A.; LÜDKE, Menga. Pesquisa em educação: abordagens qualitativas. São Paulo: EPU, 1986.

FORMOSINHO, João (coord.). Formação de professores: aprendizagem profissional e acção docente. Porto: Porto Editora, 2009.

FRANCO, Maria Laura P. B. Análise de conteúdo. 4. ed. Brasília: Liber Livro, 2012.

FREIRE, Paulo. Professora sim, tia não: cartas a quem ousa ensinar. 9. ed. São Paulo: Olho d'Água, 1998.

IMBERNÓN, Francisco. Formação docente do professorado: novas tendências. 1. ed. São Paulo: Cortez, 2009.

IMBERNÓN, Francisco. Formação continuada de professores. Porto Alegre: Artmed. 2010.

IMBERNÓN, Francisco. Formação docente e profissional: formar-se para a mudança e a incerteza. 8. ed. São Paulo: Cortez, 2011.

ISABEL Frade fala sobre alfabetização na idade certa e formação de professores. Entrevistador: Equipe Plataforma Letramento. Entrevistada: Isabel Frade. Plataforma Letramento, [S.1], [2014?]. Disponível em: http://www.plataformadoletramento.org.br. Acesso em: 10 mar. 2015.

LIBÂNEO, José Carlos. Organização e gestão da escola: teoria e prática. 5. ed. Goiânia: Editora Alternativa, 2004.

MARCELO GARCÍA, Carlos. Formação de professores: para uma mudança educativa. Porto: Porto Editora, 1999.

MARCELO GARCÍA, Carlos; VAILLANT, Denise. Ensinando a ensinar: as quatro etapas de uma aprendizagem. 1. ed. Curitiba: Ed. UTFPR, 2012.

MENSLIN, Mônica Schüler. Desenvolvimento profissional dos professores dos anos finais do ensino fundamental: as contribuições da formação continuada. 2012. 159 f. Dissertação (Mestrado em Educação) - Universidade da Região de Joinville, Joinville, 2012.

MINAYO, Maria Cecília de Souza. O desafio da pesquisa social. In: MINAYO, Maria Cecília de Souza; GOMES, Romeu; DESLANDES, Sueli Ferreira; CRUZ NETO, Otávio (org.).

Pesquisa social: teoria, método e criatividade. 27. ed. Petrópolis: Vozes, 2008. p. 9-29. 
NÓVOA, António. Para o estudo sócio-histórico da gênese e desenvolvimento da profissão docente. Teoria \& Educação, Porto Alegre, n. 4, p. 109-139, 1991a.

NÓVOA, António. Os professores: em busca de uma autonomia perdida?. In: NÓVOA, António. Ciências da Educação em Portugal - Situação actual e perspectivas. Porto, Portugal: SPCE, 1991b. p. 521-531.

NÓVOA, António. Formação de professores e trabalho pedagógico. Lisboa, Portugal: Educa 2002.

ROMANOVSKI, Joana Paulin. Formação e profissionalização docente. 3. ed. rev. e atual. Curitiba: IBPEX, 2007.

TARDIF, Maurice. Saberes docentes e formação profissional. 12. ed. Petrópolis, RJ: Vozes, 2012.

\section{$\underline{\text { SOBRE AS AUTORAS }}$}

\section{Valdicléa Machado da Silva}

Mestre em Educação pela Universidade da Região de Joinville (UNIVILLE). Professora da Rede Municipal de Educação de Joinville. E-mail: val.clea@ hotmail.com

\section{Márcia de Souza Hobold}

Doutora em Educação pela Pontifícia Universidade Católica de São Paulo (PUC/SP). Professora de Didática do Departamento de Metodologia de Ensino (MEN) e do Programa de Pós-Graduação da Universidade Federal de Santa Catarina (UFSC). E-mail: mhobold@gmail.com 